\title{
Análise do Processo de Deposição FCAW de uma Liga de Carboneto de Cromo Aplicando o Planejamento Experimental Central Composite Circumscribed
}

\author{
Gustavo Medeiros Souza do Nascimento ${ }^{1}$, Anderson Geraldo Marenda Pukasieiwcz ${ }^{1}$ \\ 1 Universidade Tecnológica Federal do Paraná - UTFPR, Departamento Acadêmico de Engenharia Mecânica, Ponta Grossa, PR, \\ Brasil.
}

Recebido: 08 Jun., 2016

Aceito: 10 Nov., 2016

E-mails: gmsnasc@gmail.com (GMSN), anderson@utfpr.edu.br (AGMP)
Este é um artigo publicado em acesso aberto (Open Access) sob a licença Creative Commons Attribution Non-Commercial, que permite uso, distribuição e reprodução em qualquer meio, sem restriçōes desde que sem fins comerciais e que 0 trabalho original seja corretamente citado.
Resumo: O aprimoramento das propriedades dos materiais como a resistência mecânica e a dureza, são importantes para a otimização de sistemas produtivos e redução dos custos de produção. O objetivo desse trabalho foi observar e analisar o comportamento da deposição de uma liga de carboneto de cromo, variando os parâmetros tensão, velocidade de soldagem e velocidade de alimentação do arame, a fim de analisar como estes influenciam a geometria do cordão de solda, microestrutura e dureza, e assim, obter configurações mais favoráveis para a deposição deste revestimento pelo processo de soldagem por arame tubular. Utilizou-se nesta pesquisa arame tubular de carboneto de cromo do tipo "metal cored" e gás de proteção Ar-25\% $\mathrm{CO}_{2}$. Na análise do processo de deposição, empregou-se o planejamento experimental Composto Central Circunscrito (CCC). Os resultados foram tratados pelo software Minitab ${ }^{\circledR}$. Observou-se que a diminuição da diluição foi obtida com o aumento da velocidade de soldagem, $34 \mathrm{~cm} / \mathrm{min}$ e diminuição da tensão. A melhor relação reforço/largura foi obtida com uma tensão na faixa de 22 a $24 \mathrm{~V}$, velocidade de soldagem na faixa de $30 \mathrm{~cm} / \mathrm{min}$ e velocidade de alimentação do arame entre 1,5 e 4,5 m/min. A maximização da dureza foi obtida para as amostras com menor diluição.

Palavras-chave: FCAW; CCC; Carboneto de cromo.

\section{Analysis of the Chromium Carbide Alloy FCAW Deposition Process Applying the Experimental Design Central Composite Circumscribed}

\begin{abstract}
The improvement of material properties such as strength and hardness, are extremely important for the optimization of the production system. The aim of this study was observe and analyze the behavior of the chromium carbide alloy deposition, varying arc tension, welding speed and wire feed speed in order to analyze welding bead geometry, microstructure and hardness, observing the most favorable configurations for the deposition of the chromium carbide alloy deposited by tubular wire welding process. It was used a cored wire chromium carbide wire and an Ar-25\% CO2 protective gas. For the analysis of the deposition process, a Central Composite Circumscribed (CCC) experimental design was used. The hardness and geometry of the weld bead were treated by Minitab software. The weld bead geometry analysis indicated that the decrease of the dilution was obtained by increasing the welding speed $34 \mathrm{~cm} / \mathrm{min}$ and decrease of the arc tension. The best height/width ratio was obtained with the arc tension between 22 and $24 \mathrm{~V}$, welding speed in the range of $30 \mathrm{~cm} / \mathrm{min}$ and between 1.5 and $4.5 \mathrm{~m} / \mathrm{min}$ wire feed speed. The results indicated that the hardness increase with the dilution reduction.
\end{abstract}

Key-words: FCAW; CCC; Chromium carbide.

\section{Introdução}

Todo o setor produtivo, utiliza algum tipo de máquina para realizar determinada função, o uso constante dos equipamentos geram um desgaste natural, que consequentemente geram um custo de manutenção, e para reduzi-los, procura-se constantemente o aperfeiçoamento dos equipamentos [1].

O mecanismo de desgaste por abrasão é definido como a perda de material inerente ao contato de duas superfícies sólidas, contendo elemento abrasivo, é um tipo de desgaste muito comum em equipamento de mineração e sucroalcooleira, por exemplo. Assim, é inevitável que os elementos das máquinas submetidas a esse tipo de desgaste, após 
Análise do Processo de Deposição FCAW de uma Liga de Carboneto de Cromo Aplicando o Planejamento Experimental Central Composite Circumscribed

determinado período de trabalho, requeiram a substituição para que o processo não seja prejudicado por falha ou queda de produtividade [2].

Atualmente busca-se novos métodos de recuperação almejando a redução dos custos devido a substituição de componentes, um exemplo aplicável é o uso de revestimentos duros nas indústrias sucroalcooleiras, onde estes revestimentos duros são depositados por diferentes processos de soldagem. A deposição visa o restabelecimento da massa perdida em trabalho, em que o posterior acabamento confere o formato original da peça [2,3].

Entre os revestimentos duros, a utilização de ligas contendo carboneto de cromo é uma opção economicamente viável, onde o processo GMAW (gas metal arc welding) é um dos processo mais utilizados, pois possibilita um melhor controle das variáveis de processo, sendo que a microscopia ótica pode ser utilizada para obter informações quanto ao mecanismo de formação dos carbonetos e a sua disposição no metal depositado [1].

O processo de deposição por meio de soldagem, contém um número grande de variáveis de processo, onde experimentar todas as combinações possíveis de parâmetros podem gerar uma grande quantidade de corpos de provas necessários para o estudo, resultando num maior custo para sua produção, assim como, as análises podem demandar muito tempo para serem concluídas [4]. Os parâmetros do processo avaliados nesse estudo, foram: tensão, velocidade de soldagem e velocidade de alimentação do arame, variando-os em três níveis. A variação dos parâmetros possibilitaram respostas quanto aos aspectos dimensionais do cordão, como diluição, penetração, largura, reforço, além de aspectos microestruturais como formação de carbonetos e microdureza.

Como alternativa para a redução do número de corridas experimentais, foi utilizado um desenho de experimento (Design of Experiment, DOE), onde se usa ferramentas estatísticas para determinar as combinações de maior relevância, reduzindo assim a quantidade de corpos de prova e, consequentemente, o custo de preparação [5,6].

O objetivo desse trabalho foi observar e quantificar o comportamento da deposição de uma liga de carboneto de cromo, variando-se os níveis de tensão, velocidade de soldagem e velocidade de alimentação do arame, analisando-se a influência destes parâmetros na geometria do cordão de solda, microestrutura e microdureza. Obtendo-se configurações mais favoráveis para a deposição de um revestimento de carboneto de cromo depositado pelo processo GMAW com arame tubular, ou mais especificamente FCAW (Flux Cored Arc Welding). Para este trabalho, escolheu-se o design experimental Composto Central Circunscrito (CCC), onde os parâmetros foco do estudo ficam dispostos em um cubo e os parâmetros adicionais, chamados de pontos axiais ou star-points, são posicionados em uma esfera que circunda o cubo. Para um trabalho preliminar, se faz muito importante a observação de parâmetros diversificados, visto que o modelo proporciona a observação de uma região mais vasta propiciada pelos parâmetros gerados, e que também pode-se apresentar os resultados por meio da Metodologia de Superfícies de Resposta (RSM - Response Surface Methodology).

\section{Materiais e Métodos}

Utilizou-se como matriz de deposição 20 chapas de aço carbono 1020, com dimensões de $155 \mathrm{~mm}$ de comprimento, $38,5 \mathrm{~mm}$ de largura e $7 \mathrm{~mm}$ de espessura. Para deposição utilizou-se arame tubular de 1,6 mm de diâmetro, a composição química com porcentagem em massa fornecida pelo fabricante é apresentada na Tabela 1.

O processo de deposição do metal, foi realizado no Laboratório de Soldagem da Universidade Tecnológica do Paraná - Campus Ponta Grossa, utilizando a equipamento marca ESAB, modelo Smashweld 315, com faixas de tensão do arco elétrico de 20 a $30 \mathrm{~V}$ e corrente na faixa de 50 a 315 A, o gás utilizado para os experimentos era composto de Argônio (75\%) e $\mathrm{CO}_{2}$ (25\%).

Tabela 1. Composição química do arame tubular.

\begin{tabular}{|c|c|c|c|c|c|c|}
\hline Material & C & Si & Mn & $\mathrm{Cr}$ & $\mathbf{P}$ & $\mathbf{S}$ \\
\hline $\begin{array}{c}\text { Arame } 1,6 \mathrm{~mm} \\
\text { Composição fornecida pelo fabricante } \\
\text { (porcentagem em massa \%) }\end{array}$ & 4,40 & 0,3 & 0,30 & 27,0 & N.D. & N.D. \\
\hline
\end{tabular}

N.D. Não Determinada. 
O deslocamento da tocha durante a soldagem foi realizado pelo equipamento Tartílope V1, capaz de movimentar-se em velocidade constante no eixo $X$, possibilitando uma soldagem uniforme. Os dados para corrente e tensão foram obtidos mediante a utilização de dois sensores por Efeito Hall, para a obtenção dos dados de tensão utilizou-se o sensor LV 20-P e para a corrente o LF 505-S, ambos transcritos no software Lab View Signal Express ${ }^{\circledR}$.

A sequência experimental foi gerado pelo software Minitab ${ }^{\circledR}$, o qual fornece uma planilha com a ordem experimental em diversos modelos de design experimental, em ordem aleatória onde pôde-se observar o comportamento do sistema de soldagem e aquisição de dados, pois observado as mudanças na configuração do sistema para cada experimento foi possível observar a influência de erros aleatórios. Os parâmetros iniciais são apresentados na Tabela 2.

Os parâmetros apresentados na Tabela 2, foram os objetos iniciais do estudo e foram dispostos em um cubo. $O$ design escolhido, permitiu a inserção de parâmetros não previstos, os star-points, esses parâmetros são dispostos em uma esfera que envolve o cubo, o raio dessa esfera simbolizado pela letra grega Alfa (a) gerado automaticamente pelo software com a=1,68, e que pode ser obtida conforme Equação 1 abaixo:

Tabela 2. Parâmetros experimentais iniciais.

\begin{tabular}{cccc}
\hline NíVEIS & $\begin{array}{c}\text { Tensão } \\
\text { (V) }\end{array}$ & $\begin{array}{c}\text { Velocidade de Soldagem } \\
(\mathbf{c m} / \mathbf{m i n})\end{array}$ & $\begin{array}{c}\text { Velocidade de Alimentação do Arame } \\
(\mathbf{m} / \mathbf{m i n})\end{array}$ \\
Baixo & 22 & 25 & 2,00 \\
Médio & 24 & 30 & 3,25 \\
Alto & 26 & 35 & 4,50 \\
\hline
\end{tabular}

$$
\propto=\left(2^{n}\right)^{1 / 4}
$$

onde: $\mathrm{n}$ é o número de parâmetros analisados.

O desenho experimental, ou seja, a disposição gráfica dos parâmetros do experimento, onde o cubo representa os parâmetros iniciais e a esfera circunscrita com os pontos axiais [4], são apresentados na Figura 1.

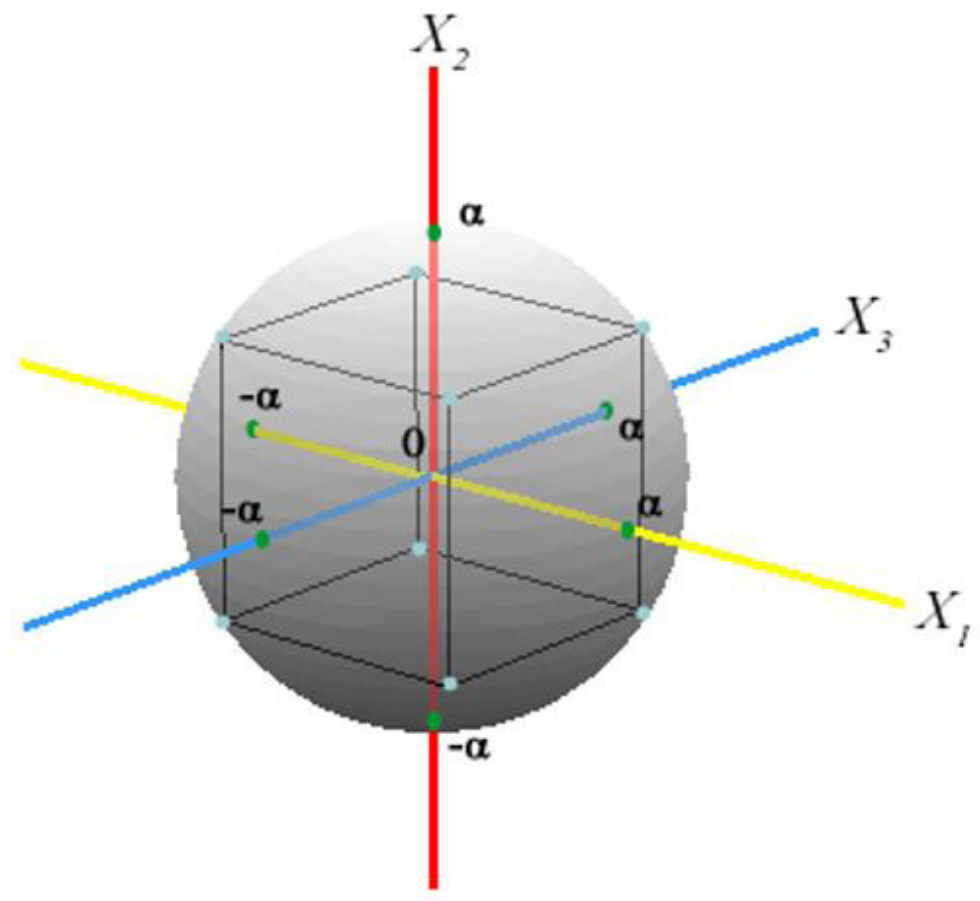

Figura 1. Representação gráfica do DOE-CCC. Fonte: Minitab [7]. 
Análise do Processo de Deposição FCAW de uma Liga de Carboneto de Cromo Aplicando o Planejamento Experimental Central Composite Circumscribed

A ordem experimental gerada pelo Minitab $^{\circledR}$ é apresentada na Tabela 3.

Tabela 3. Parâmetros de soldagem utilizados.

\begin{tabular}{cccccccc}
\hline Ordem & $\begin{array}{c}\text { Tensão } \\
\text { (V) }\end{array}$ & $\begin{array}{c}\text { Velocidade de } \\
\text { Soldagem } \\
\text { (cm/min) }\end{array}$ & $\begin{array}{c}\text { Velocidade de } \\
\text { Alimentação do } \\
\text { Arame } \\
\text { (m/min) }\end{array}$ & Ordem & $\begin{array}{c}\text { Tensão } \\
\text { (V) }\end{array}$ & $\begin{array}{c}\text { Velocidade de } \\
\text { Soldagem } \\
\text { (cm/min) }\end{array}$ & $\begin{array}{c}\text { Velocidade de } \\
\text { Alimentação do } \\
\text { Arame } \\
\text { (m/min) }\end{array}$ \\
$\mathbf{1}$ & 24 & 30 & 3,25 & $\mathbf{1 1}$ & 26 & 35 & 2,00 \\
$\mathbf{2}$ & 22 & 35 & 4,50 & $\mathbf{1 2}$ & 24 & 30 & 3,25 \\
$\mathbf{3}$ & 24 & 30 & 3,25 & $\mathbf{1 3}$ & 24 & 30 & 5,53 \\
$\mathbf{4}$ & 24 & 30 & 3,25 & $\mathbf{1 4}$ & 22 & 25 & 4,50 \\
$\mathbf{5}$ & 26 & 25 & 2,00 & $\mathbf{1 5}$ & 24 & 30 & 3,25 \\
$\mathbf{6}$ & 24 & 30 & 1,15 & $\mathbf{1 6}$ & 24 & 21,5 & 3,25 \\
$\mathbf{7}$ & 26 & 35 & 4,50 & $\mathbf{1 7}$ & 26 & 25 & 4,50 \\
$\mathbf{8}$ & 24 & 30 & 3,25 & $\mathbf{1 8}$ & 22 & 35 & 2,00 \\
$\mathbf{9}$ & 22 & 25 & 2,00 & $\mathbf{1 9}$ & 24 & 38,5 & 3,25 \\
$\mathbf{1 0}$ & 20,6 & 30 & 3,25 & $\mathbf{2 0}$ & 27,4 & 30 & 3,25 \\
\hline
\end{tabular}

Os cordões foram inspecionados por meio de ensaio não destrutivo por líquidos penetrantes, para avaliar a qualidade superficial do cordão e a presença de poros e trincas.

Para a avaliação microestrutural e microdureza, preparou-se as amostras dos cordões de solda com embutimento com resina baquelite, após corte das amostras. Para a avaliação dos aspectos de geometria do cordão, utilizou-se microscópio ótico Zeiss Imager A2.m. As dimensões do cordão de solda foram obtidos por meio do software de análise Axio Imager 2. O ensaio de microdureza Vickers foi realizado no microdurômetro Shimadzu HMV - 20G, com a configuração de carga de 300 gf durante $15 \mathrm{~s}$, foram realizadas 3 medidas no metal base, 1 na linha de fusão e 6 no metal de depositado, dispostos em uma linha vertical num total de dez medidas, o procedimento foi realizado em triplicata para cada amostra, sendo apresentado o valor médio. O ensaio de Microdureza foi realizado segundo a norma ASTM E384, Standard Test Method for Microindentation Hardnees of Materials [8].

Os valores obtidos das análises foram tratadas pelo software Minita $b^{\circledR}$, onde os resultados foram apresentados em gráficos de superfícies de resposta. A análise de microestrutura foi realizada tanto por microscopia ótica, em equipamento Zeiss A2.m, como eletrônica de varredura em equipamento Tescan modelo Vega 3. A análise de composição química foi realizada em equipamento EDS marca Oxford acoplado ao MEV Tescan modelos Vega 3.

\section{Resultados e Discussões}

\subsection{Análise da geometria dos cordões}

Com auxílio do software Axio Imager 2, obteve-se as dimensões do cordão de solda, a diluição do metal base, e com isso obteve-se a o índice de convexidade, IC, dos cordões de solda, que é basicamente a relação entre o reforço e a largura do cordão. Segundo trabalho conduzido por Silva et al. [9], cordões com condições aceitáveis deste índice, apresentam uma relação próxima a 30\%. Os dados obtidos para a geometria de cordão são apresentados na Tabela 4.

Analisando-se inicialmente o IC da Tabela 4 é possível observar que os cordões 1, 5, 6 e 14 foram os cordões que apresentaram valores de IC mais próximos a 30\%. Pode-se também constatar que estes cordões também apresentaram os maiores valores de diluição, todos acima de $25 \%$.

Os dados obtidos são também representados pelos gráficos de superfícies de respostas abaixo, indicando com isso, e de forma mais rápida o comportamento da geometria dos cordões com os parâmetros de processo. Optou-se por estabelecer duas variáveis de processo a serem apresentados nos eixos x e y dos gráficos e o terceiro parâmetro recebeu o seu valor médio, com o valor da diluição obtido no eixo Z, para a Figura 2.

A Figura 2 representa a superfície de resposta combinando velocidade de deslocamento com a tensão (a) e velocidade de alimentação (b). 
Tabela 4. Resultados experimentais de diluição, largura, reforço e penetração.

\begin{tabular}{cccccccccc}
\hline Amostra & $\begin{array}{c}\text { Diluição } \\
\text { (\%) }\end{array}$ & $\begin{array}{c}\text { Largura } \\
(\mathbf{m m})\end{array}$ & $\begin{array}{c}\text { Reforço } \\
(\boldsymbol{\mu} \mathbf{m})\end{array}$ & $\begin{array}{c}\text { Relação IC } \\
\text { (índice de } \\
\text { convexi- } \\
\text { dade) }\end{array}$ & $\begin{array}{c}\text { Amostra } \\
\text { Amiluição } \\
\mathbf{( \% )}\end{array}$ & $\begin{array}{c}\text { Largura } \\
(\mathbf{m m})\end{array}$ & $\begin{array}{c}\text { Reforço } \\
\text { (mm) }\end{array}$ & $\begin{array}{c}\text { Relação IC } \\
\text { (índice de } \\
\text { convexidade) }\end{array}$ \\
$\mathbf{1}$ & 25 & 4,3 & 1,7 & 39,6 & $\mathbf{1 1}$ & 16 & 3,3 & 2,5 & 75,4 \\
$\mathbf{2}$ & 18 & 2,8 & 2,4 & 85,5 & $\mathbf{1 2}$ & 18 & 3,6 & 1,9 & 53,3 \\
$\mathbf{3}$ & 23 & 3,6 & 1,9 & 52,5 & $\mathbf{1 3}$ & 17 & 3,4 & 2,6 & 76,8 \\
$\mathbf{4}$ & 21 & 4,1 & 2,0 & 49,7 & $\mathbf{1 4}$ & 30 & 3,6 & 1,5 & 42,2 \\
$\mathbf{5}$ & 32 & 4,4 & 1,7 & 38,8 & $\mathbf{1 5}$ & 20 & 3,1 & 1,9 & 60,7 \\
$\mathbf{6}$ & 24 & 3,9 & 1,6 & 41,3 & $\mathbf{1 6}$ & 14 & 3,7 & 2,8 & 74,9 \\
$\mathbf{7}$ & 23 & 4,2 & 2,2 & 51,8 & $\mathbf{1 7}$ & 12 & 3,4 & 2,7 & 78,8 \\
$\mathbf{8}$ & 19 & 3,4 & 2,2 & 65,2 & $\mathbf{1 8}$ & 18 & 3,1 & 1,8 & 59,4 \\
$\mathbf{9}$ & 17 & 3,3 & 2,1 & 64,5 & $\mathbf{1 9}$ & 16 & 3,0 & 2,1 & 71,1 \\
$\mathbf{1 0}$ & 15 & 3,1 & 2,3 & 72,4 & $\mathbf{2 0}$ & 21 & 4,4 & 2,1 & 46,7 \\
\hline
\end{tabular}
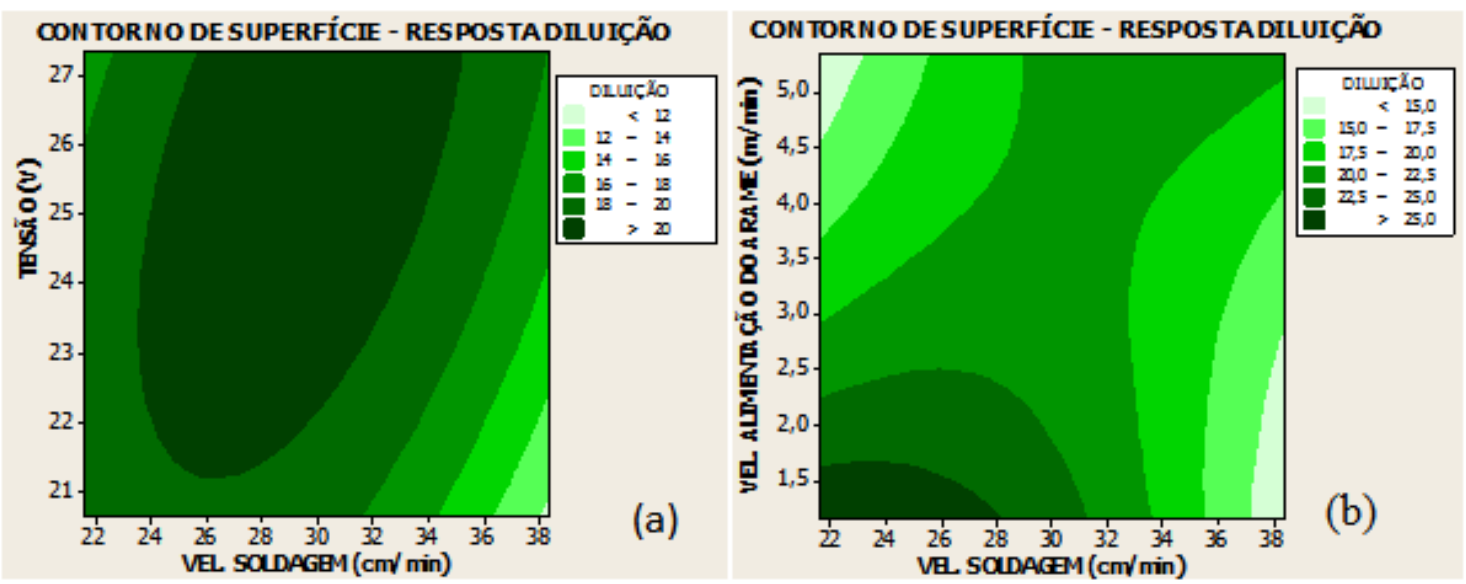

Figura 2. Contorno de superfície de resposta para a influência da Velocidade de Soldagem e Tensão (a) e Velocidade de Soldagem e de alimentação (VA*) (b) na Diluição. (a) Velocidade de alimentação do arame mantida a 3,25 m/min e (b) Tensão mantida em 24 V.

Pela observação dos gráficos foi possível definir que as melhores configurações do sistema para se obter a menor diluição apresentam uma velocidade de soldagem superior a $34 \mathrm{~cm} / \mathrm{min}$ e uma ampla faixa de valores de tensão, Figura 2a, desde que utilizado velocidade de soldagem superior a $34 \mathrm{~cm} / \mathrm{min}$. Ao passo que o aumento da velocidade de alimentação de arame geraram uma redução dos percentuais de diluição, as faixas onde se verifica tal comportamento foram obtidas velocidades de soldagem superiores a $34 \mathrm{~cm} / \mathrm{min}$ e velocidade de alimentação de arame superiores a $3,5 \mathrm{~m} / \mathrm{min}$.

Apesar de que a menor diluição é interessante do ponto de vista microestrutural, deve-se salientar que uma menor diluição provoca uma redução significativa no IC do depósito, afetando a geometria do mesmo. É possível perceber na Figura 2a que a alteração da velocidade de soldagem afeta de forma mais significativa a diluição que a tensão, onde a diluição apresenta um patamar mais elevado para uma velocidade de soldagem inferior a $30 \mathrm{~cm} / \mathrm{min}$ para uma ampla faixa de tensão. O efeito do aumento da diluição com a redução da velocidade de soldagem, deve-se ao aumento do aporte térmico decorrente desta alteração. Entretanto para que ocorra o aumento de diluição de forma mais significativa, deve-se aumentar a tensão, gerando um maior comprimento de arco, proporcionando uma coluna de plasma mais ampla em sua extensão, ou seja, tornando o cordão de solda mais largo e achatado aumentando a diluição e reduzindo o reforço, acarretando o aumento do IC [10].

Na Figura $2 b$ também verifica-se que a velocidade de soldagem afeta de forma mais significativa a diluição que a velocidade de alimentação do arame. Pode-se constatar portanto, que a alteração na Energia de soldagem, devido à mudança na velocidade de soldagem, foi mais efetiva na variação da diluição que a alteração na quantidade 
Análise do Processo de Deposição FCAW de uma Liga de Carboneto de Cromo Aplicando o Planejamento Experimental Central Composite Circumscribed

de material depositado. Uma das formas que pode ser utilizada para minimizar a diluição e aumentar o índice de convexidade é o uso de tecimento [10], entretanto esta técnica não foi utilizada neste trabalho.

Analisando-se os resultados obtidos a partir dos contornos de superfície da Figura 2 e Tabela 4, pode ser observado que para manter uma relação dimensional do cordão IC próximo a 30\%, amostras 1 e 5, deve-se elevar a diluição para valores acima de $20 \%$. Para isso deve-se selecionar uma tensão na faixa de 22 a $26 \mathrm{~V}$, velocidade de soldagem na faixa de $30 \mathrm{~cm} / \mathrm{min}$, para uma ampla faixa de valores de velocidade de alimentação do arame.

Os dados obtidos para a variação da largura com a tensão, velocidade de soldagem e velocidade de alimentação do arame, são apresentados na Figura 3.
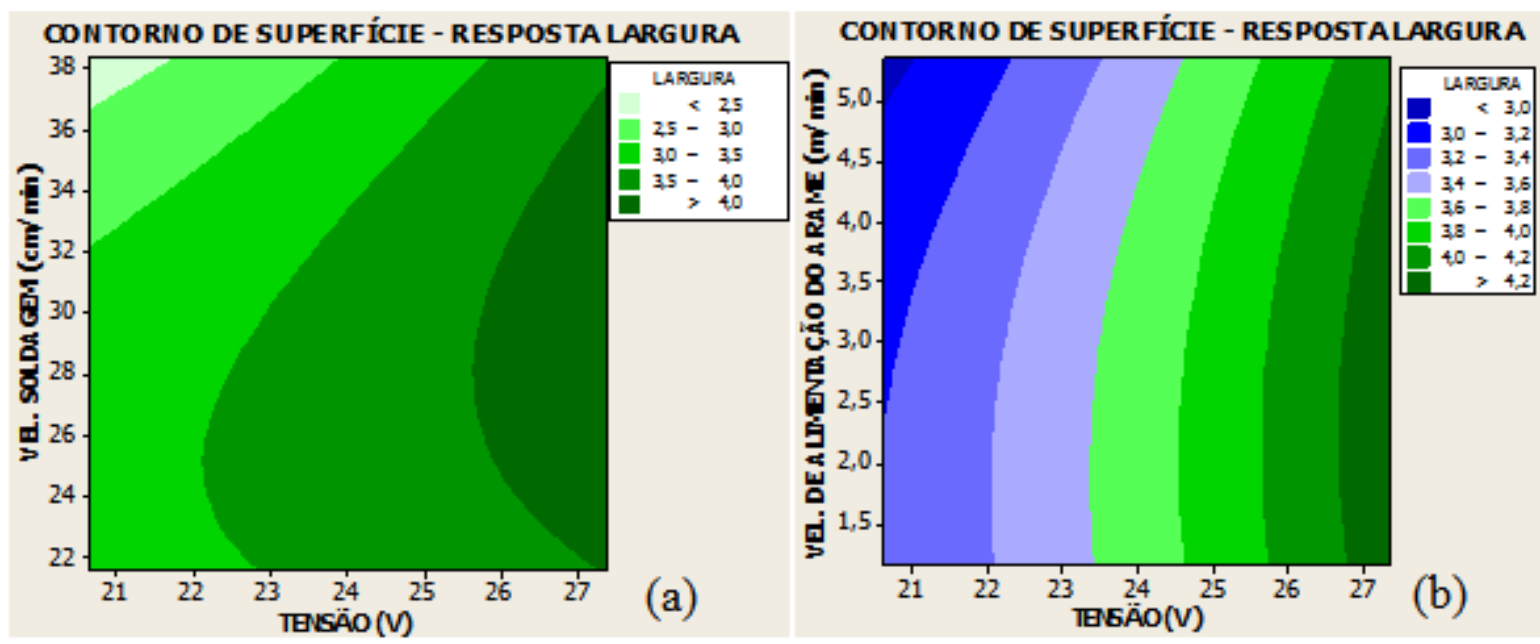

Figura 3. Contorno de superfície de resposta para a influência da Velocidade de Soldagem (VS*) e Tensão (a) e Velocidade de alimentação do arame (VA*) e tensão (b) na Largura. (a) Velocidade de alimentação do arame mantida a $3,25 \mathrm{~m} / \mathrm{min}$ e (b) Velocidade de Soldagem mantida em $30 \mathrm{~cm} / \mathrm{min}$.

Os contornos de superfície de resposta, para o efeito dos parâmetros na largura, indicam que a alteração da velocidade de soldagem e velocidade de alimentação do arame geram pouca alteração na largura dos cordões, sendo a variação da tensão o fator mais significativo na largura. Esta análise está de acordo com o discutido por Pessoa et al. [10], onde a maior largura do arco voltaico proporcionado pelo aumento da tensão, gera um aumento na largura do cordão do revestimento. Para a faixa de valores analisados, e considerando uma maior largura como o ideal, a melhor configuração, foi a adoção de tensão acima de $26 \mathrm{~V}$, velocidade de soldagem entre 22 a $35 \mathrm{~cm} / \mathrm{min}$, e velocidade de alimentação abaixo de 4,0 m/min, apresentando assim os maiores valores de largura para esse experimento.

Assim como a largura dos cordões, a influência dos parâmetros de deposição no reforço também foi analisada, sendo os resultados demonstrados na Figura 4.

A análise dos gráficos da Figura 4 possibilita estabelecer como a alteração dos parâmetros pode ser realizada para minimizar o reforço. Percebe-se que a minimização do reforço é obtida com menores velocidades de alimentação do arame, Figura $4 \mathrm{~b}$ reduzindo assim o volume de material depositado, e valores intermediários de velocidade de soldagem. Em relação à tensão observa-se uma menor influência, entretanto os menores valores de reforço foram obtidos com tensões intermediárias, entre 20 e 24V, Figura 4a. Neste caso é possível estabelecer que os parâmetros para os menores valores de reforço são, velocidade de soldagem entre 30 e $35 \mathrm{~cm} / \mathrm{min}$ e velocidade de alimentação de $2 \mathrm{~m} / \mathrm{min}$ com ajuste de tensão médio entre 20 e $24 \mathrm{~V}$.

Deve-se salientar que do ponto de vista de geometria do cordão o aspecto mais importante que deve ser analisado é o Índice de Convexidade, neste ponto a minimização da tensão, com valores entre 22 e $24 \mathrm{~V}$, a manutenção da velocidade de soldagem em $30 \mathrm{~cm} / \mathrm{min}$ propiciou a deposição de cordões com melhores geometrias. 

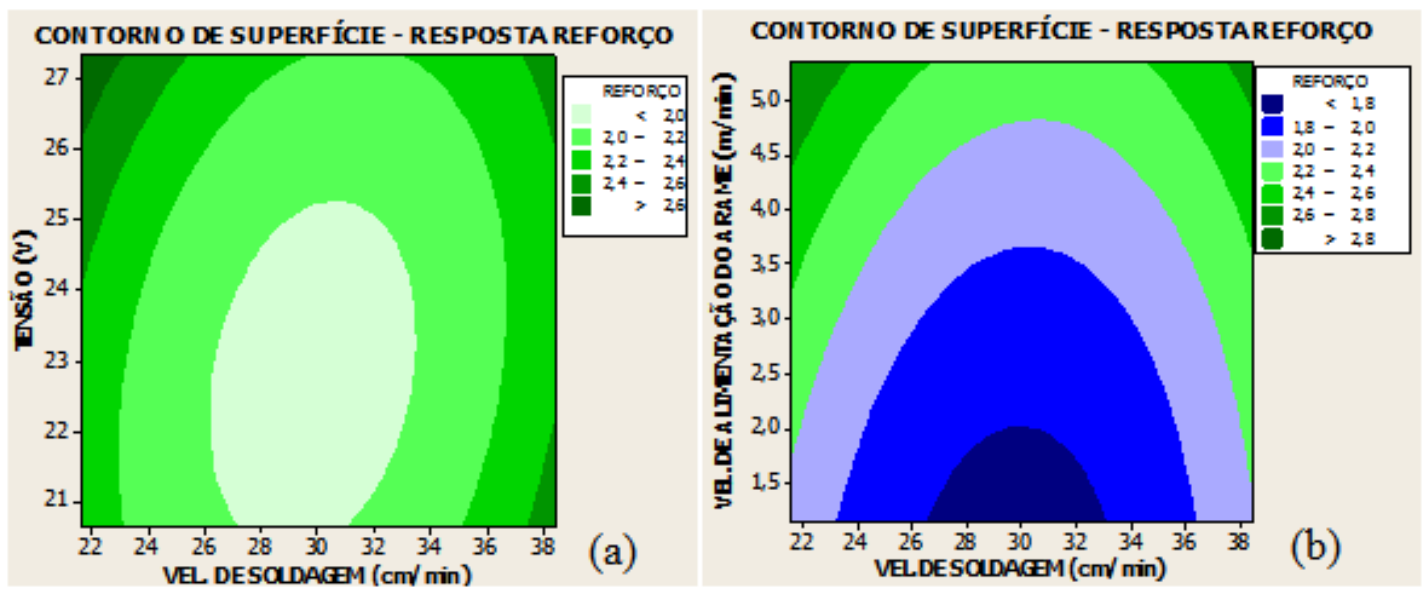

Figura 4. Contorno de superfície de resposta para a influência da Velocidade de Soldagem e Tensão (a) e Velocidade de alimentação do arame (VA*) e Velocidade de Soldagem (b) no reforço do cordão de solda. (a) Velocidade de alimentação do arame mantida a 3,25 m/min e (b) Tensão mantida em 24V.

\subsection{Análise da microestrutura e microdureza dos cordões depositados}

A análise de microestrutura foi realizada em amostras com diferentes valores de diluição, procurando-se avaliar a sua influência na microestrutura dos cordões depositados. Os valores de diluição mais elevados foram obtidos com as amostras 5 e 14, com 32\% e 30\% respectivamente. As Figura 5 a 7 ilustram as microestruturas observadas nestas amostras.

As duas amostras apresentam uma divisão bem definida entre a microestrutura da região superior do cordão, com a microestrutura da região central e inferior. Na região superior no topo do cordão de solda das duas amostras, Figura 6a, é possível observar a formação de carbonetos de cromo primários, sem uma orientação definida, e a estrutura eutética. A outra região, localizada no restante do cordão, é caracterizada como uma microestrutura eutética, sem a formação de carbonetos primários, conforme ilustrado na Figura 6b.

Nestas amostras é observado que a formação de carbonetos primários é suprimida com a maior diluição presente nestas amostras. Observa-se que a formação de carbonetos primários ocorre somente na região superior das amostras, onde ocorre um menor efeito da diluição do metal base. Segundo Chang et al. [11], a variação da concentração de carbono promove uma alteração no formato dos carbonetos. Os carbonetos formados são do tipo $(\mathrm{Cr}, \mathrm{Fe})_{7} \mathrm{C}_{3}$, neste caso os carbonetos primários alteram o formato de acordo com a concentração de carbono, mantendo-se no formato de agulhas.

As amostras que apresentaram as diluições com valores intermediários, selecionadas para a avaliação da microestrutura, foram a amostra 1, com 25\% e a amostra 6, com 24\%, observadas na Figura 7.

Comparando-se as imagens das amostras 5 e 14 com as amostras 1 e 6, observa-se que a formação de carbonetos primários ocupa uma maior extensão do cordão, conforme indicado nas Figuras que ilustram toda a seção transversal do cordão. Assim como observado nas amostras 5 e 14, a região superior do cordão apresenta a formação de carbonetos primários, enquanto que as demais regiões são formadas por estrutura eutética, Figura 8.

Os valores mais baixos para diluição foram obtidos com as amostras 16 com 14\% e com a amostra 17 com $11 \% . \%$, como pode ser visto na Figura 9.

Os revestimentos com menor diluição apresentaram uma microestrutura distinta das demais, com a formação de carbonetos primários na forma de agulhas, na região central e inferior do cordão de solda, enquanto que na região superior do cordão observou-se a presença de carbonetos primários na forma poligonal. Esta microestrutura poligonal também foi observada no trabalho conduzido por Chang et al. [12].

No trabalho conduzido por Chang et al. [13], a presença de carbonetos na forma poligonal apresentam uma resistência ao deslizamento superior ao do revestimento composto por carbonetos na forma de agulhas. A elevada resistência ao desgaste, propiciada por estes carbonetos, também foi avaliada nos trabalhos conduzidos por Leite e Marques [2] e Lima e Ferraresi [14]. 

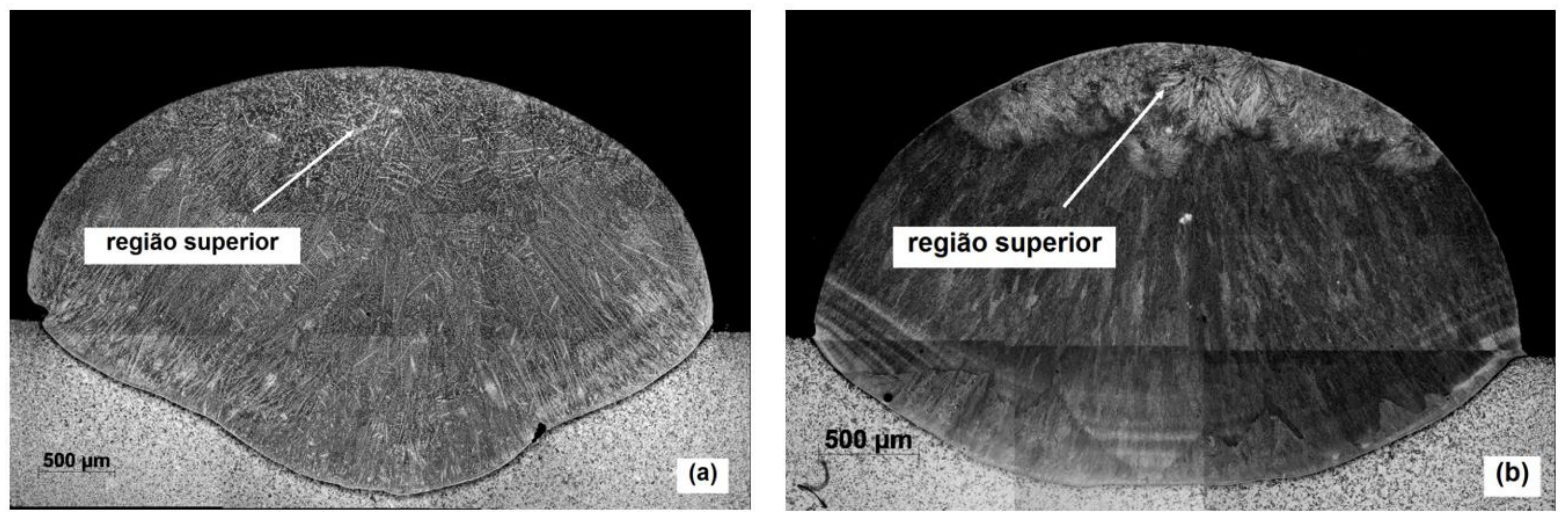

Figura 5. (a) Micrografia da amostra 5; (b) Micrografia da amostra 14.
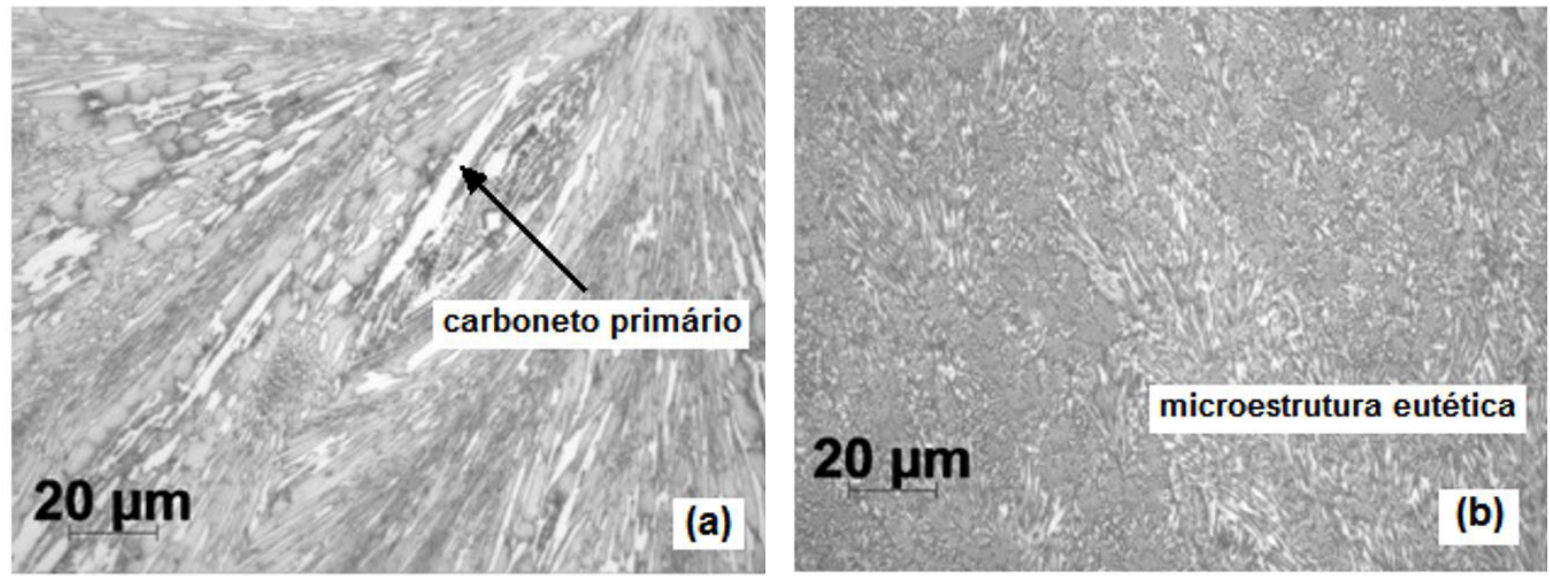

Figura 6. Microestrutura dos carbonetos observada na amostra 14, (a) região superior; (b) região inferior e central

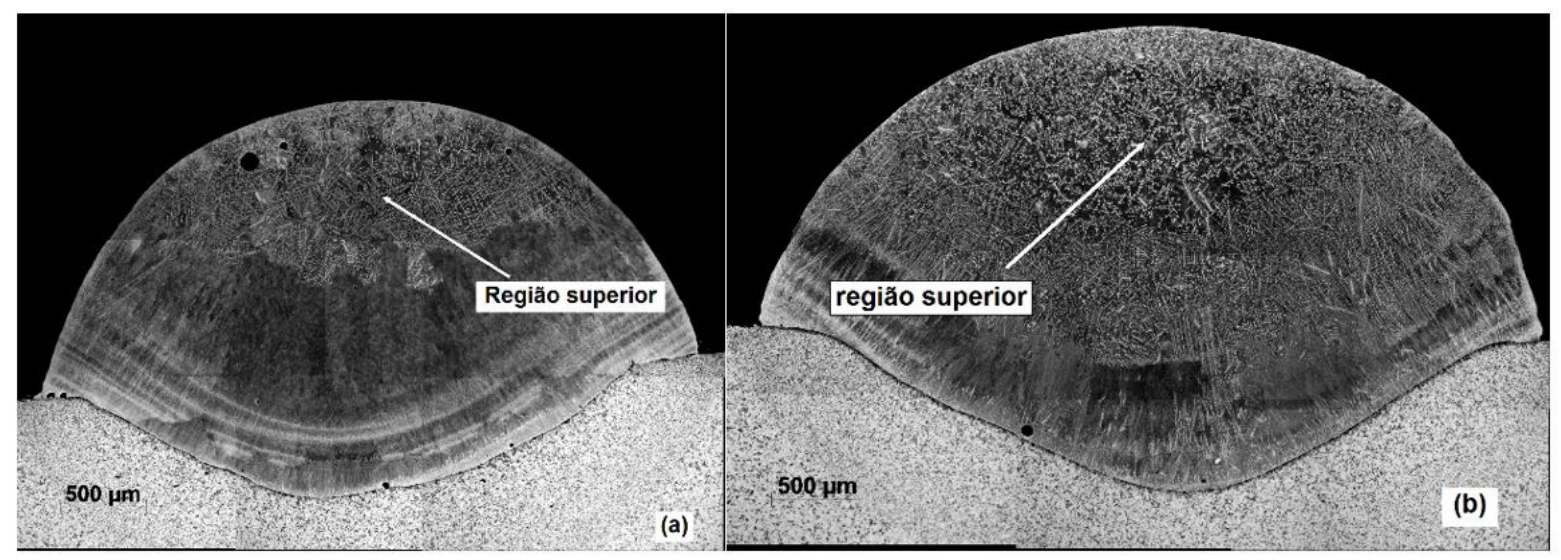

Figura 7. (a) Micrografia da amostra 1; (b) Micrografia da amostra 6.

A formação dos carbonetos poligonais foi acompanhada por um aumento na quantidade de cromo devido a menor diluição dos revestimentos. Esta maior concentração de cromo, deve ser acompanhada também de uma maior concentração de carbono. No trabalho conduzido por Chang et al. [11], observou-se a formação de carbonetos poligonais, em detrimento da forma de agulhas, com o aumento do teor de carbono. Além desta característica, observou-se também que os carbonetos primários na forma de agulhas apresentaram um crescimento ao longo do sentido do fluxo de calor, e também o aumento da nucleação de carbonetos quando estes apresentam-se na 

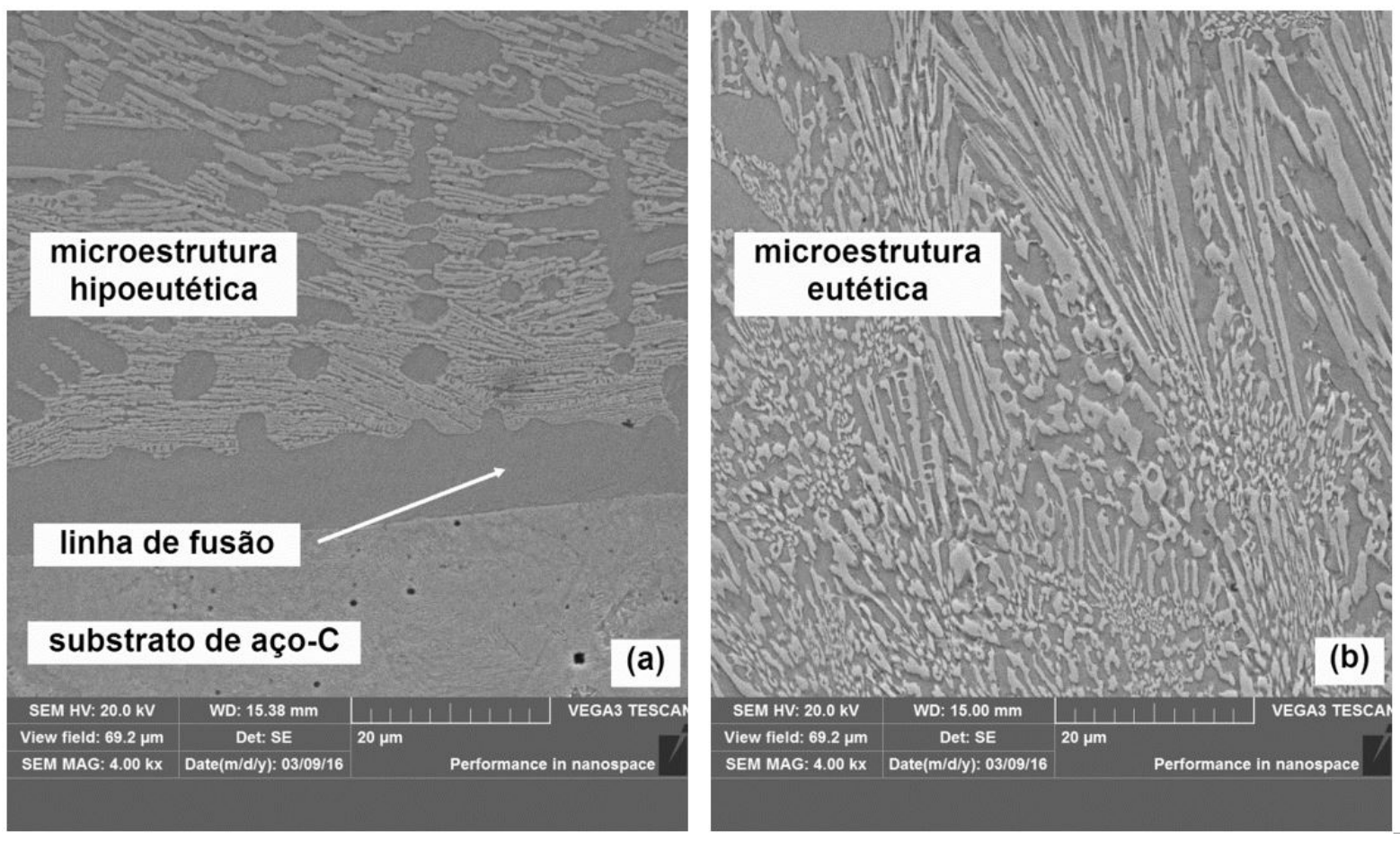

Figura 8. Micrografia da amostra 6 (a) região inferior próximo a linha de fusão; (b) região central.

forma de polígonos. A formação dos carbonetos de cromo, na forma poligonal localizados na região central e superior do cordão, são observados na Figura 10.

A variação da composição química das amostras com os diferentes parâmetros de deposição explica as diferentes formações de microestrutura que os revestimentos apresentaram, Figura 11.
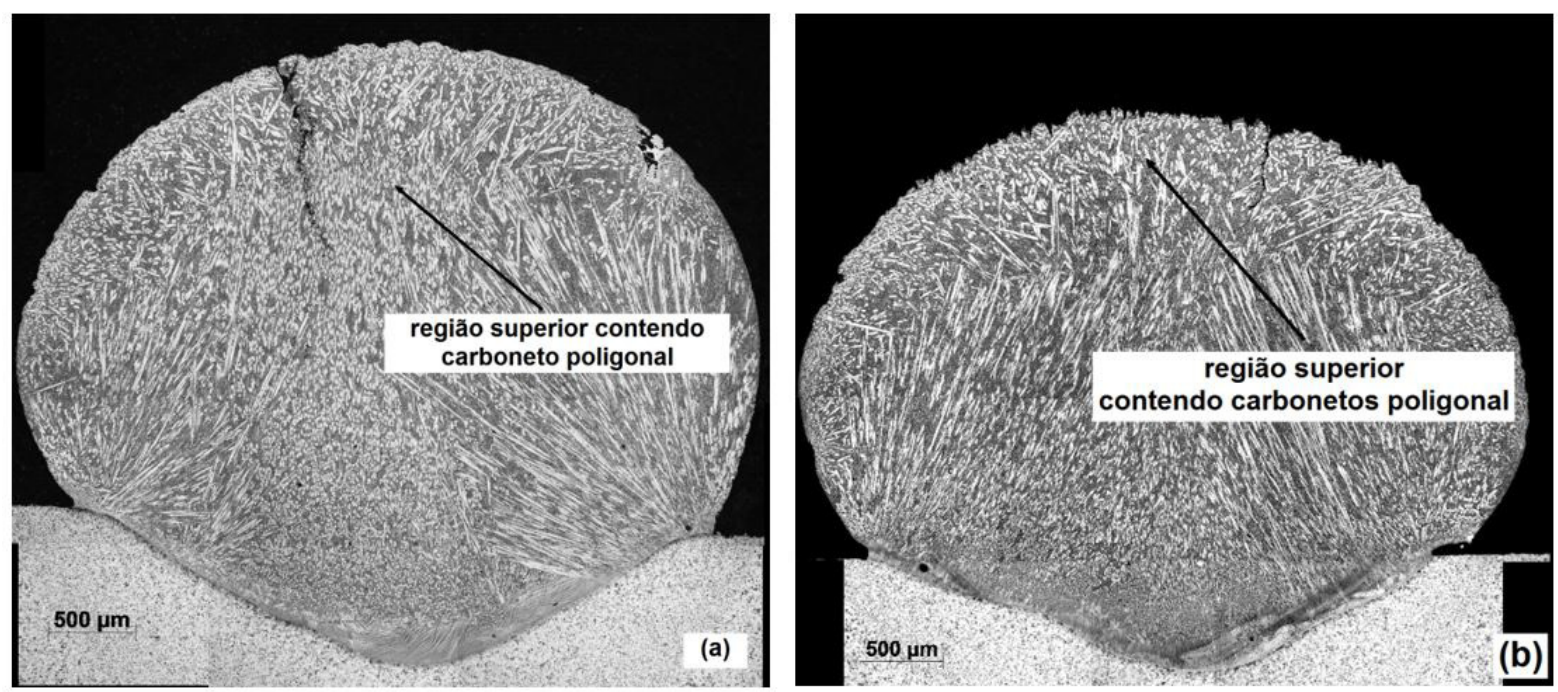

Figura 9. (a) Micrografia da amostra 16; (b) Micrografia da amostra 17.

A amostra 05 com maior diluição apresentou um menor teor de Cromo até uma distância de $0,5 \mathrm{~mm}$, posteriormente apresentou uma composição de Cromo muito semelhante à da amostra 01 , com diluição ligeiramente menor. Esta semelhança na composição química pode ser observada na microestrutura, com a presença de uma microestrutura predominantemente eutética. Já a amostra 16 com diluição muito inferior à das demais amostras 

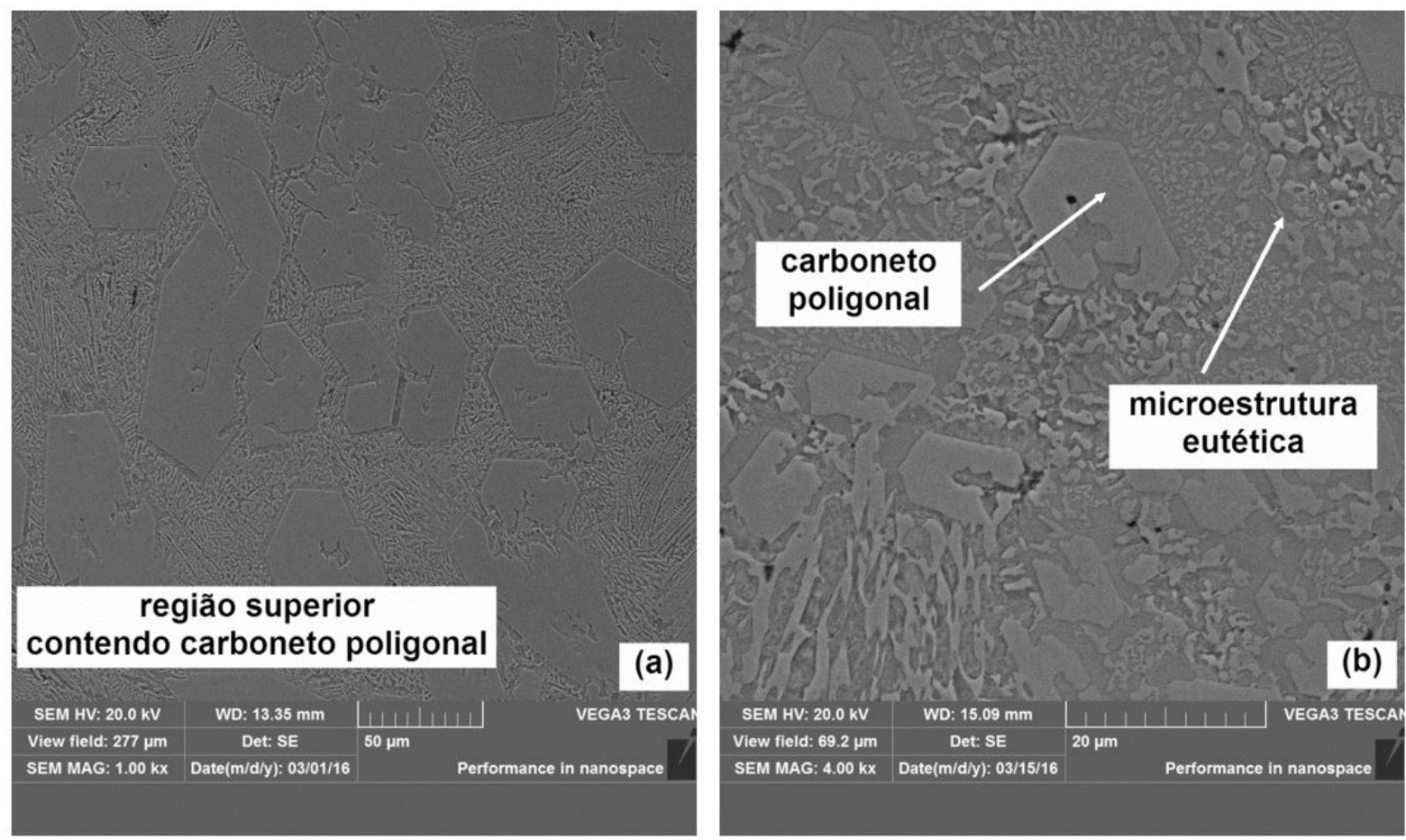

Figura 10. Formação de carbonetos na região central da amostra 16 (a) visão geral; (b) detalhe da formação do carboneto poligonal.

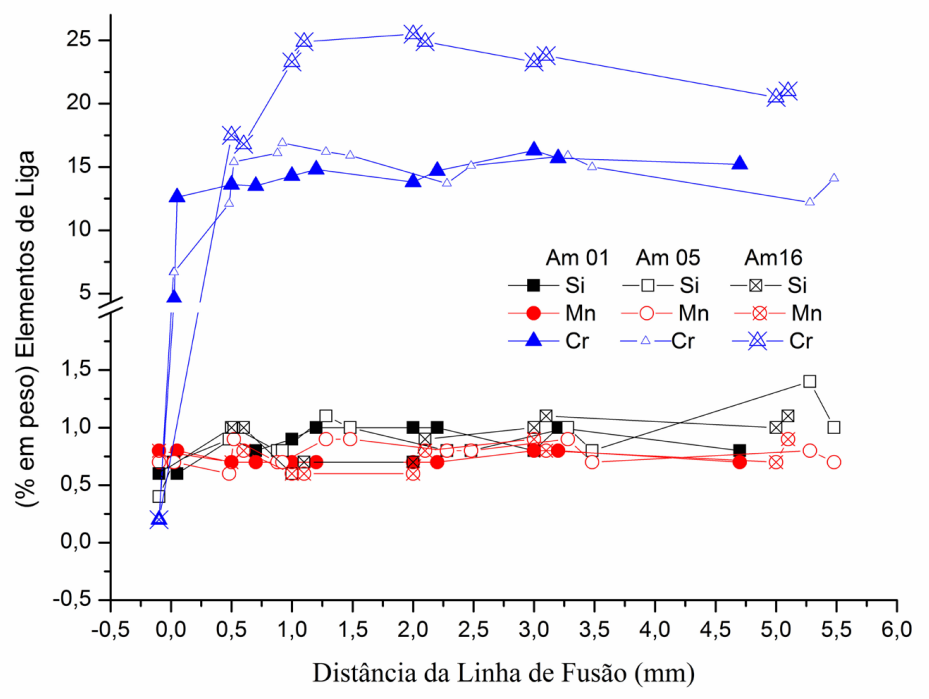

Figura 11. Perfil de Composição Química das Amostras 01, 05 e 16.

apresentou um teor bem mais elevado de Cromo, muito próximo da composição nominal do arame, que é de $27,0 \%$ em peso. é importante destacar que a formação de carbonetos de Cromo poligonais aparentemente, não dependeu apenas do teor de Cromo, e consequentemente de Carbono da liga. A formação de carbonetos de cromo poligonais ocorreu principalmente na região superior do cordão de solda. A formação desta microestrutura em maior quantidade no topo do cordão pode ser decorrente da maior taxa de nucleação existentes nesta região, devido às diferentes condições de resfriamento impostas nas diferentes regiões do cordão depositado. 
A microdureza está intrinsecamente ligada a formação da microestrutura do cordão de solda, guardando uma relação muito estreita com a diluição, pois quanto menor a diluição observou-se a formação de carbonetos de maior resistência no revestimento, ou seja, aumenta-se a dureza do cordão de solda, Figura 12.

Na Figura 12 é possível observar a influência dos parâmetros de deposição no perfil de dureza dos revestimentos depositados, nesta Figura constata-se que os revestimentos com menor diluição apresentaram um maior valor de dureza, em decorrência da maior formação de carbonetos poligonais, que as amostras com maior diluição [13].

De posse desses resultados inseriu-se na planilha de trabalho do software Minitab ${ }^{\circledR}$, para obter os contornos superfícies de respostas para cada objeto de estudo. $O$ foco foi a obtenção dos gráficos que traduzem o comportamento do experimento e do sistema em que ele foi realizado. Os dados obtidos pelo ensaio de microdureza Vickers resulta na superfície de resposta apresentada pela Figura 12.

$\mathrm{Na}$ Figura 13b é possível observar que a utilização de tensões intermediárias geraram amostras com maior valor de dureza, enquanto que maiores velocidades de alimentação de arame propiciaram um aumento na dureza dos cordões Figura 13b. Já a velocidade de soldagem não apresentou uma definição muita clara de seu efeito na dureza dos revestimentos. As variações que permitiram um aumento no valor de dureza dos revestimentos foram aqueles que permitiram uma diminuição da diluição dos revestimentos.

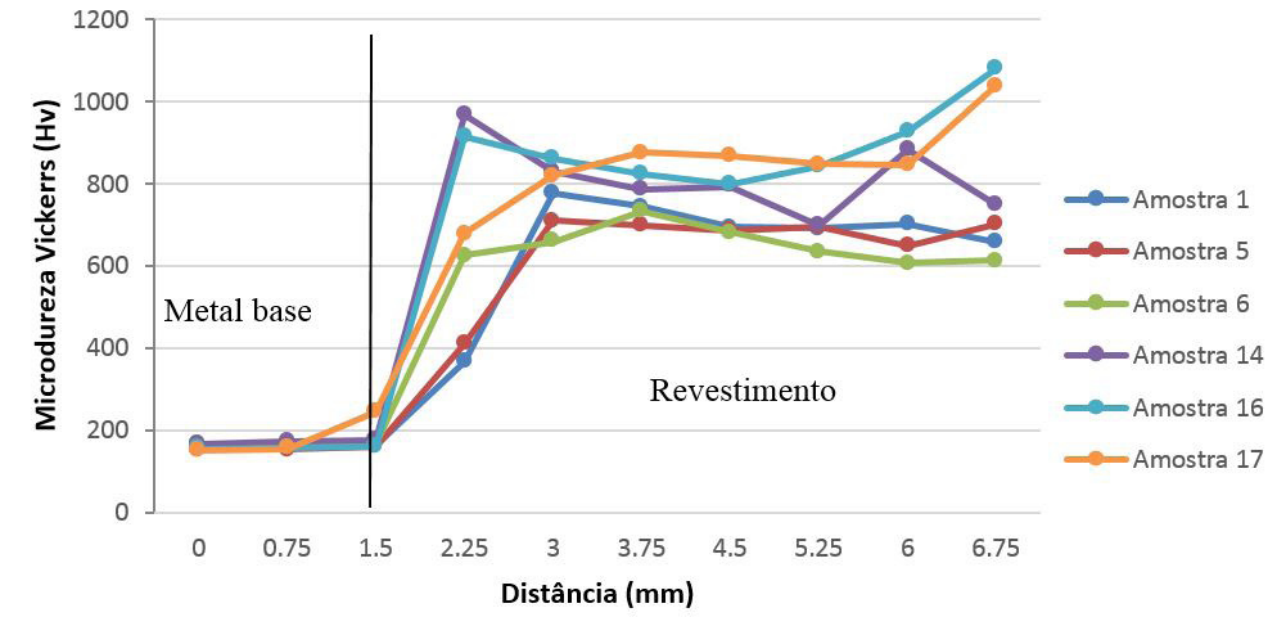

Figura 12. Perfil de Microdureza Vickers das amostras analisadas.
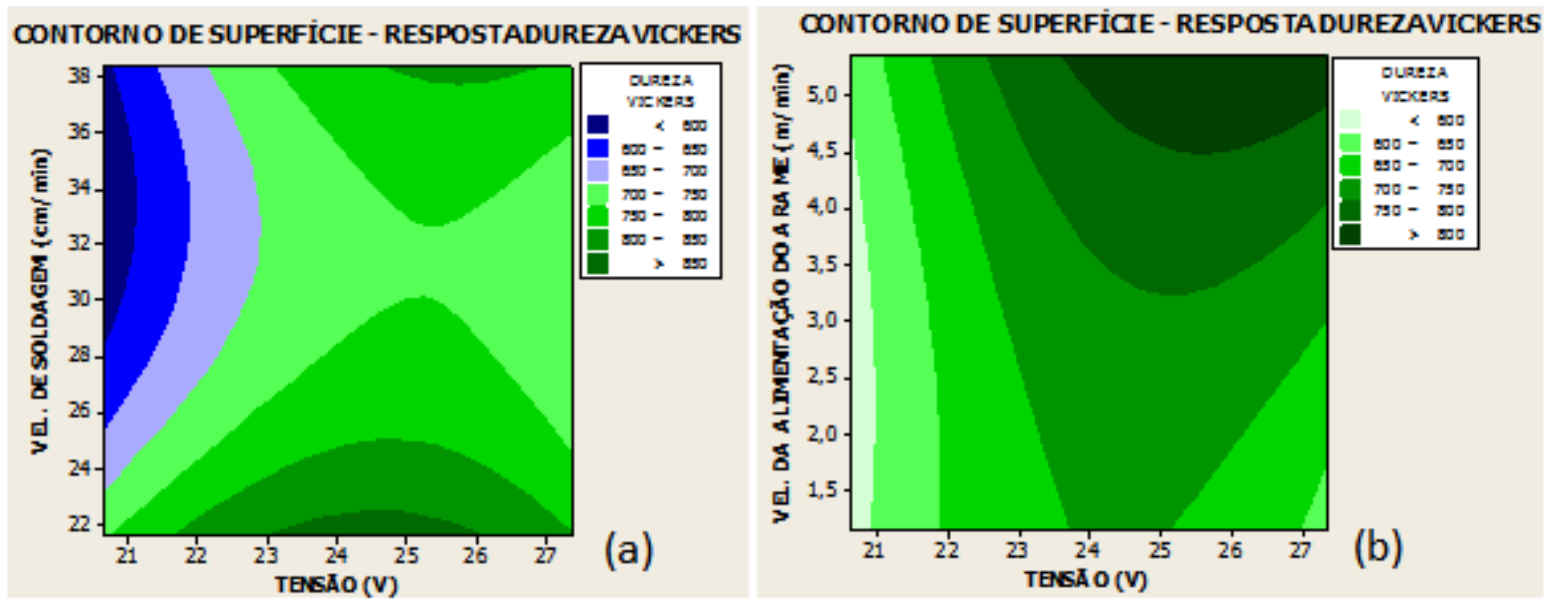

Figura 13. Contorno de superfície de resposta para a influência da Velocidade de Soldagem (VS*) e Tensão (a) e Velocidade de alimentação do arame (VA*) e Tensão (b) na microdureza Vickers dos revestimentos. (a) Velocidade de soldagem mantida a $30 \mathrm{~cm} / \mathrm{min}$ e (b) Velocidade de alimentação do arame mantida em 3,25 m/min. 
Análise do Processo de Deposição FCAW de uma Liga de Carboneto de Cromo Aplicando o Planejamento Experimental Central Composite Circumscribed

\section{Conclusões}

Após o estudo da influência da tensão, velocidade soldagem e velocidade de alimentação do arame comportamento na deposição de uma liga de carboneto de cromo, utilizando desenho de experimento do tipo Composto Central Circunscrito, foi possível concluir que:

- O desenho de experimento CCC cumpriu o papel de proporcionar uma investigação abrangente do estudo, com um número que reduzido de amostra em face a todas as combinações possíveis que o fatorial completo proporcionaria.

- Os contorno de superfície de resposta tornaram as análises mais rápidas e simples, considerando simultaneamente todos os parâmetros, levando sempre em consideração o parâmetro que se pode melhorar e controlar.

- Observou-se que a combinação de parâmetros que obteve melhor geometria do cordão foi obtida com os seguintes parâmetros: uma tensão na faixa de 22 a $25 \mathrm{~V}$, velocidade de soldagem na faixa de $30 \mathrm{~cm} / \mathrm{min}$ e ampla faixa de velocidade de alimentação do arame, entre 1,15 e 4,5 $\mathrm{m} / \mathrm{min}$ de velocidade de alimentação do arame.

- A minimização de diluição foi obtida com velocidade de soldagem de pelo menos $35 \mathrm{~cm} / \mathrm{m}$, alimentação de arame de 3,0 $\mathrm{m} / \mathrm{min}$ e valores de tensão inferiores a $24 \mathrm{~V}$.

- A maximização da dureza foi obtida para as amostras com menor diluição, com dureza entre 900 e $1100 \mathrm{Hv}$, entretanto estes parâmetros não depositaram os cordões com melhor geometria.

\section{Referências}

[1] Macedo BPN, Trevisan LA, Crespo GS, Manera RS, Ventrella VA, Gallego J. Revestimentos duros depositados por soldagem: o papel dos carbonetos sobre a resistência ao desgaste abrasivo. In: Anais do 36을 Congresso Nacional de Soldagem (CONSOLDA); 2010; Recife, PE. São Paulo: Associação Brasileira de Soldagem; 2010.

[2] Leite RV, Marques PV. Estudo comparativo da resistência ao desgaste abrasivo do revestimento de três ligas metálicas utilizadas na indústria, aplicadas por soldagem com arames tubulares. Soldagem \& Inspeção. 2009;14(4):329-335. http:// dx.doi.org/10.1590/S0104-92242009000400007.

[3] Lima AC, Siqueira IL, Morais LI, Oliveira FP, Morais VP No. Soldagem de revestimentos duros em facas picadoras de cana-de-açúcar de indústria sucroalcooleira: eletrodo revestido "versus" arame tubular. In: Anais do 70 Congresso Norte Nordeste de Pesquisa e Inovação (CONNEPI); 2012; Palmas, TO. Palmas: CONNEPI; 2012. (vol. 1).

[4] Barros B No, Scarminio IS, Bruns RE. Planejamento e otimização de experimentos. Campinas: Editora Unicamp; 1996.

[5] Box GEP, Hunter WG, Hunter JS. Statistics for experimenters: an introduction to design, data analysis and model building. Nova York: Wiley; 1978.

[6] Montgomery DC. Design and analysis of experiments. 6th ed. New York: Wiley; 2005.

[7] Minitab. State College; 2016 [acesso em 8jun. 2016]. Disponível em: https://www.minitab.com/pt-BR/

[8] ASTM International. ASTM E384-01: standard test method for microindentation hardnees of materials. West Conshoncken: ASTM; 2011.
[9] Silva, Ferraresi VA, Scotti A. A quality and cost approach for welding process selection. Journal of the Brazilian Society of Mechanical Sciences. 2000;22(3):389-398. http://dx.doi. org/10.1590/S0100-73862000000300002.

[10] Pessoa ARP, Miranda HC, Farias JP, Aguiar WM, Assis F Fo. Seleção de parâmetros através do método taguchi para soldagem de revestimento com ligas de níquel pelo processo MIG/MAG. Soldagem \& Inspeção. 2010;15(4):317-324. http:// dx.doi.org/10.1590/S0104-92242010000400009.

[11] Chang $\mathrm{CH}$, Lin CM, Hsieh CC, Chen JH, Fan CM, Wu W. Effect of carbon content on microstructural characteristics of the hypereutectic $\mathrm{Fe}-\mathrm{Cr}-\mathrm{C}$ claddings. Materials Chemistry and Physics. 2009;117(1):257-261. http://dx.doi.org/10.1016/j. matchemphys.2009.05.052.

[12] Chang C-M, Chen Y-C, Wu W. Microstructural and abrasive characteristics of high carbon $\mathrm{Fe}-\mathrm{Cr}-\mathrm{C}$ hardfacing alloy. Tribology International. 2010;43(5-6):929-934. http://dx.doi. org/10.1016/j.triboint.2009.12.045.

[13] Chang CC, Chen L, Lin C, Chen J, Fan C, Wu W. Microstructure and wear characteristics of hypereutectic $\mathrm{Fe}-\mathrm{Cr}-\mathrm{C}$ cladding with various carbon contents. Surface and Coatings Technology. 2010;205(2):245-250. http://dx.doi.org/10.1016/j. surfcoat.2010.06.021.

[14] Lima AC, Ferraresi VA. Análise da microestrutura e da resistência ao desgaste de revestimento duro utilizado pela indústria sucro-alcooleira. Soldagem \& Inspeção. 2009;14(2):140-150. http://dx.doi.org/10.1590/S0104-92242009000200006. 